\title{
Decoupling Analysis of Water Environmental Pressure and Economic Growth in Shanghai
}

\author{
Aixiang Tao \\ School of Business, HuaiYin Institute of Technology, Huai an, China
}

\begin{abstract}
While developing our economy, we also attach great importance to pollution prevention and control in order to improve the environmental quality. Water environmental pollution is an important part of environmental pollution. It is very meaningful to alleviate the pressure of water environment through the prevention and control of water environmental pollution. This paper uses decoupling theory to analyze the relationship between water environmental pressure and economic growth in Shanghai. The results show that, there is a strong decoupling between water environmental pressure and economic growth in Shanghai. The main reason is the transformation of industrial structure and the increase of investment in science and technology.
\end{abstract}

\section{INTRODUCTION}

At present, China has entered a critical period of building a well-off society in an all-round way. A well-off society needs not only the sustainable development of economy, but also the continuous improvement of environment. How to improve China's environment while sustaining economic development is a topic of great concern to all sectors of society. The pressure of water environment is caused by the pollution of water environment, which brings pressure to the development of economy and society. Scholars have conducted in-depth research on the relationship between water environment and economy, and achieved a series of research results.

Wang Ting and other scholars have studied the coupling relationship between Beijing's economy and water environment system and its effect. The results show that the coupling degree between the economic system and the water environment system in Beijing is basically consistent with the water resources efficiency, showing an upward trend as a whole[1]. Tong Guoping and Chen Yan studied the coordinated development of the water environment-social-economic system in the Huaihe River Basin. The results showed that the water environment, social and economic systems of the provinces in the Huaihe River Basin were developing better and better [2]. Wang Lin and others discussed the coupling between economic growth and water environment change [3]. Fang Lin and others analyzed the long-term and short-term effects of economic restructuring on water environment quality in the basin, and put forward some policy recommendations [4]. Taking Fujian Province as an example, Rao Tsinghua and others analyzed the coupling coordination degree of social economy and water environment quality in the basin, and put forward corresponding suggestions [5]. Changyumiao studied the coupling model of water resources environment and urban eco-economic system, and made corresponding evaluation [6]. Wu Yepeng and others analyzed the coordination of water resources, environment and economy and society in the Silk Road Economic Belt [7]. Zhang Hengquan and others decoupled the industrial water environmental pressure from economic growth in the Yangtze River Economic Zone. The results show that the industrial water environmental pressure in the Yangtze River economic zone presents a good trend from weak decoupling to strong decoupling, and the decoupling coefficients and decoupling status of different regions have temporal and spatial differences [8]. Feng Ying and others have studied the relationship between water pollution and economic growth in China. The results show that China's economic development and water pollution interact with each other. There is a significant "N-shaped" curve relationship between water pollution emissions and per capita GDP [9].

Based on the existing research results of scholars, this paper uses decoupling theory to study the relationship between water environmental pressure and economic growth in Shanghai, and draws corresponding conclusions.

\section{Data and methods}

\subsection{Research data}

There are many indicators to measure the water environmental pressure. In this paper, the total amount of wastewater discharge and the total amount of chemical oxygen demand of wastewater are selected as the 
indicators to measure the water environmental pressure in Shanghai. This paper takes the total GDP of past years as an index to measure the level of Shanghai 's economic growth. The data in this paper are derived from
Shanghai Statistical Yearbook, and the data from 2008 to 2018 are selected. The data of water environmental pressure and economic growth in Shanghai are as follows:

Table 1 Total unit of wastewater discharge in Shanghai unit: 100 million tons

\begin{tabular}{lrrrrrrrrrr}
\hline & 2008 & 2009 & 2010 & 2011 & 2012 & 2013 & 2014 & 2015 & 2016 & 2017 \\
\hline $\begin{array}{l}\text { Total unit } \\
\text { Of water } \\
\text { discharge }\end{array}$ & 22.60 & 23.05 & 24.82 & 19.86 & 22.05 & 22.30 & 22.12 & 22.41 & 22.08 & 21.20 \\
\hline
\end{tabular}

Table 2 Total unit of chemical oxygen demand of wastewater in Shanghai unit: 10,000 tons

\begin{tabular}{lcccccccccc}
\hline & 2008 & 2009 & 2010 & 2011 & 2012 & 2013 & 2014 & 2015 & 2016 & 2017 \\
\hline $\begin{array}{l}\text { Total Chemical } \\
\text { Oxygen Demand }\end{array}$ & 26.67 & 24.34 & 21.98 & 24.90 & 24.26 & 23.56 & 22.44 & 19.88 & 14.75 & 14.18 \\
$\begin{array}{l}\text { Emission of } \\
\text { waste water }\end{array}$ & & & & & & & & & \\
\hline
\end{tabular}

Table 3 Shanghai GDP gross unit: 100 million yuan

\begin{tabular}{rrrrrrrrrrl}
\hline & 2008 & 2009 & 2010 & 2011 & 2012 & 2013 & 2014 & 2015 & 2016 & 2017 \\
\hline GDP & 14277 & 15288 & 17437 & 19539 & 20559 & 22264 & 24068 & 25659 & 28183 & 30633 \\
\hline
\end{tabular}

\subsection{Research methods}

Referring to the calculation model of decoupling index proposed by OECD and the research results of foreign scholars Tapio and domestic scholars, this paper constructs the following decoupling elastic coefficient model:

$$
\begin{aligned}
& \mathrm{I}_{\mathrm{n}+1}= \frac{\left(C P_{n}+1-C P_{n}\right) / C P_{n}}{\left(Y F_{n}+1-Y F_{n}\right) / Y F_{n}} \\
& \mathrm{H}_{\mathrm{n}+1}=\frac{\left(D P_{n}+1-D P_{n}\right) / D P_{n}}{\left(Y F_{n}+1-Y F_{n}\right) / Y F_{n}}
\end{aligned}
$$

In the formula (1), $\mathrm{n}$ is the nth year, $\mathrm{In}+1$ is the elasticity coefficient of decoupling between total wastewater discharge and total GDP in the year, $\mathrm{CPn}+1$ and $\mathrm{CPn}$ refer to the total wastewater discharge in different year, YFn+1 and YFn refer to the total GDP in different year.

In the formula (1), $\mathrm{n}$ is the $\mathrm{nth}$ year, $\mathrm{Hn}+1$ is the elasticity coefficient of decoupling between total chemical oxygen demand of wastewater and total GDP in the year, DPn +1 and DPn refer to the total chemical oxygen demand of wastewater in different year, YFn+1 and YFn refer to the total GDP in different year. $\triangle \mathrm{CP}=\mathrm{CPn}+1-\mathrm{CPn} ; \triangle \mathrm{DP}=\mathrm{DPn}+1-\mathrm{DPn}$, $\triangle \mathrm{YF}=\mathrm{YFn}+1-\mathrm{YFn}$

In this paper, the decoupling state is divided into the following eight types: the decoupling elastic coefficient $\mathrm{I} 1=0.8$ and $\mathrm{I} 2=1.2$, which are used by foreign scholars Tapio and others

Table 4 Types of decoupling between total wastewater discharge and total economic growth in Shanghai

\begin{tabular}{llc}
\hline & Decoupling condition & decoupling state \\
\hline $\mathrm{I} \leq 0$ & $\triangle \mathrm{CP}<0, \triangle \mathrm{YF}>0$ & absolute decoupling(AD) \\
$\mathrm{I} \leq 0$ & $\triangle \mathrm{CP}>0, \triangle \mathrm{YF}<0$ & absolute negative decoupling(AND) \\
$0<\mathrm{I} \leq 0.8$ & $\triangle \mathrm{CP}>0, \triangle \mathrm{YF}>0$ & weak decoupling(WD) \\
$0<\mathrm{I} \leq 0.8$ & $\triangle \mathrm{CP}<0, \triangle \mathrm{YF}<0$ & weak negative decoupling(WND) \\
$0.8<\mathrm{I} \leq 1.2$ & $\triangle \mathrm{CP}>0, \triangle \mathrm{YF}>0$ & expansion connection(EC) \\
$0.8<\mathrm{I} \leq 1.2$ & $\triangle \mathrm{CP}<0, \triangle \mathrm{YF}<0$ & decline connection(DC) \\
$\mathrm{I}>1.2$ & $\triangle \mathrm{CP}>0, \triangle \mathrm{YF}>0$ & expansion negative decoupling(END) \\
$\mathrm{I}>1.2$ & $\triangle \mathrm{CP}<0, \triangle \mathrm{YF}<0$ & recessive decoupling(RD) \\
\hline
\end{tabular}

Table 5 Types of decoupling between total chemical oxygen demand (COD) of wastewater and total economic growth in Shanghai

\begin{tabular}{llc}
\hline & Decoupling condition & decoupling state \\
\hline $\mathrm{I} \leq 0$ & $\triangle \mathrm{DP}<0, \triangle \mathrm{YF}>0$ & absolute decoupling(AD) \\
$\mathrm{I} \leq 0$ & $\triangle \mathrm{DP}>0, \triangle \mathrm{YF}<0$ & absolute negative decoupling(AND) \\
$0<\mathrm{I} \leq 0.8$ & $\triangle \mathrm{DP}>0, \triangle \mathrm{YF}>0$ & weak decoupling(WD) \\
$0<\mathrm{I} \leq 0.8$ & $\triangle \mathrm{DP}<0, \triangle \mathrm{YF}<0$ & weak negative decoupling(WND) \\
$0.8<\mathrm{I} \leq 1.2$ & $\triangle \mathrm{DP}>0, \triangle \mathrm{YF}>0$ & expansion connection(EC) \\
\hline
\end{tabular}




\begin{tabular}{lcc}
\hline $0.8<\mathrm{I} \leq 1.2$ & $\triangle \mathrm{DP}<0, \triangle \mathrm{YF}<0$ & decline connection(DC) \\
$\mathrm{I}>1.2$ & $\triangle \mathrm{DP}>0, \triangle \mathrm{YF}>0$ & expansion negative decoupling(END) \\
$\mathrm{I}>1.2$ & $\triangle \mathrm{DP}<0, \triangle \mathrm{YF}<0$ & recessive decoupling(RD) \\
\hline
\end{tabular}

\section{Data analysis results}

in Shanghai can be obtained by analyzing the relevant data, the results are as follows.

According to the above formulas, the decoupling coefficients between total wastewater discharge and GDP

Table 6 Decoupling coefficient between total wastewater discharge and GDP in Shanghai

\begin{tabular}{lccccccccc}
\hline & 2009 & 2010 & 2011 & 2012 & 2013 & 2014 & 2015 & 2016 & 2017 \\
\hline Decoupling coefficient & 0.280 & 0.544 & -1.65 & 2.12 & 0.137 & -0.099 & 0.198 & -0.150 & -0.458 \\
\hline
\end{tabular}

Table 7. Decoupling state between total wastewater discharge and total GDP in Shanghai

\begin{tabular}{llllllllll}
\hline & 2009 & 2010 & 2011 & 2012 & 2013 & 2014 & 2015 & 2016 & 2017 \\
\hline Decoupling state & WD & WD & AD & END & WD & AD & WD & AD & AD \\
\hline
\end{tabular}

Table 8 The decoupling coefficient between total chemical oxygen demand (COD) and GDP of wastewater in Shanghai

\begin{tabular}{lccccccccl}
\hline & 2009 & 2010 & 2011 & 2012 & 2013 & 2014 & 2015 & 2016 & 2017 \\
\hline Decoupling coefficient & -1.23 & -0.688 & 1.098 & -0.494 & -0.348 & -0.587 & -1.729 & -2.633 & -0.444 \\
\hline
\end{tabular}

Table 9 Decoupling state between total chemical oxygen demand of wastewater and total GDP in Shanghai

\begin{tabular}{llllllllll}
\hline & 2009 & 2010 & 2011 & 2012 & 2013 & 2014 & 2015 & 2016 & 2017 \\
\hline Decoupling state & AD & AD & EC & AD & AD & AD & AD & AD & AD \\
\hline
\end{tabular}

\section{Conclusion and Discuss}

From the above results, we know that the total amount of wastewater discharged in Shanghai is basically decoupled from the total economic amount. From 2009 to 2017, there were four years in absolute decoupling, four years in weak decoupling and one year in negative expansion decoupling. The decoupling between the total chemical oxygen demand (COD) of wastewater and the total economic growth in Shanghai is more obvious. From 2009 to 2017, there were eight years in absolute decoupling and one year in expanding connection. The above data demonstrate that the positive interaction between economic growth and water environment has been achieved in Shanghai, and the economic growth of Shanghai is no longer at the expense of water environment. From 2008 to 2017, the total GDP of Shanghai increased by $115 \%$, while the total wastewater discharge decreased by $6.19 \%$ and the total chemical oxygen demand of wastewater decreased by $46.83 \%$.

One of the main reasons for this phenomenon is the adjustment of industrial structure. From 2008 to 2017, the proportion of primary industry and secondary industry in Shanghai's GDP structure showed a downward trend year by year, while the proportion of tertiary industry showed the above trend year by year. Obviously, the growth of the tertiary industry depends less on water resources, so the amount of wastewater generated increases less, and the discharge of chemical oxygen demand in wastewater will gradually decrease. Second, investment in science and technology has increased. From 2008 to 2017, Shanghai's investment in science and technology increased from 12.03 billion yuan to 38.99 billion yuan, with a growth rate of $224 \%$. A large increase in investment in science and technology has led to a significant improvement in the level of science and technology in Shanghai. Obviously, due to the improvement of science and technology level, Shanghai's economic growth can be shifted to the track of relying on scientific and technological progress, which can achieve sustained and stable economic growth while reducing environmental pollution.

Table 10 Shanghai GDP Component Unit: \%

\begin{tabular}{lllllllllll}
\hline & 2008 & 2009 & 2010 & 2011 & 2012 & 2013 & 2014 & 2015 & 2016 & 2017 \\
\hline $\begin{array}{l}\text { primary } \\
\text { industy }\end{array}$ & 0.8 & 0.7 & 0.7 & 0.7 & 0.6 & 0.6 & 0.5 & 0.5 & 0.4 & 0.3 \\
$\begin{array}{l}\text { secondary } \\
\text { industry } \\
\text { third }\end{array}$ & 55.5 & 40.2 & 42.3 & 41.6 & 39.2 & 36.6 & 35.1 & 32.2 & 29.8 & 30.5 \\
industry & 59.1 & 57.0 & 57.7 & 60.2 & 62.8 & 64.4 & 67.3 & 69.8 & 69.2 \\
\hline
\end{tabular}


Table 11 Shanghai Local Finance Expenditure Unit on Science and Technology unit: \$100 million

\begin{tabular}{|c|c|c|c|c|c|c|c|c|c|}
\hline 2008 & 2009 & 2010 & 2011 & 2012 & 2013 & 2014 & 2015 & 2016 & 2017 \\
\hline $\begin{array}{l}\text { Science and } 120.3 \\
\text { Technology } \\
\text { expenditure }\end{array}$ & 215.3 & 202.0 & 218.5 & 245.4 & 257.7 & 262.3 & 271.9 & 341.7 & 389.9 \\
\hline
\end{tabular}

\section{Reference}

1. Wang Ting,Wang Bao-qian,Cao Ting-ting.Research on the Coupling Relationship and Effect of Beijing's Economic System and Water Environment Systema[J]. Rural Water Conservancy and Hydropower in China,2017 (2) : 77-82

2. Tong Guo-ping,Chen Yan.Study on Coordinated Development of Water Environment-Social-Economy System in Huaihe River Basin[J].Resource Development \& Market,2018,34(8):1086-1093

3. Wang Lin,Wang Jin,Kang Hui-min,Sun Yi-ke,Zhang Xiang-zhong.The Coupling Relationship Between Economic Development and Water Environment Change[J].Mathematics in Practice and Theory, 2019(4):64-71

4. Fang Lin, $\mathrm{Wu}$ Fengping,Zhang Qinghai.Analysis of Short and Long-term Effect of Economic Structural Adjustment on Water Environment in the Basin[J].China Population, Resources and Environment,2017,27(11):176-184

5. Rao Qing-hua,Lin Xiu-zhu,Li Jia-bing,Chen Qi,Chen Wen-hua.Analysis of Coupling Coordination Between Social Economy and Water Environment Quality in River Basin[J].China Environmental Science,2019,39(4):1784-1792

6. Chang Yu-miao.System Coupling Model and Evaluation of Water Resources Environment and Urban Eco-economy[J].Water Resources and Power,2018,36(2):56-60

7. Wu Yepeng, Yuan Ruhua,Liu Shiyuan.Analysis of Coordination Between Water Resources \& Environment and the Economy and Society along the Silk Road Economic Belt[J].Ecological Economy,2017,33(9):153-160

8. $\mathrm{Xu}$ Jing,Wang Zeyu.Spatial and Temporal Differentiation of China's Land-sea Coordination Performance and Influencing Factors:Based on Vulnerability Perspective[J]. Areal Research and Development,2019,38(2):13-19

9. Feng Ying,Li Xiaoning,Qu Guojun,Xu Mei.Study on Water Environmental Pollution and Economic Growth in China[J].Journal of Northwest A \& F University(Social

Science

Edition), 2017,17(6):67-75 